Supporting Information for:

\title{
Kinetic Control of Length and Morphology of Segmented Polymeric Nanofibers in Microfluidic Chips
}

Zhengping Tan, Zaiyan Hou, Ke Wang, Yuce Li, Lianbin Zhang, Jintao Zhu, Jiangping Xu*

Key Laboratory of Material Chemistry for Energy Conversion and Storage of Ministry of Education (HUST), and State Key Laboratory of Materials Processing and Die \& Mold Technology, School of Chemistry and Chemical Engineering, Huazhong University of Science and Technology (HUST), Wuhan 430074, China

*Corresponding Authors: E-mail: jiangpingxu@hust.edu.cn (J.X.)

Number of pages: 12

Number of figures: 11

Number of tables: 0

Number of schemes: 0

\section{Contents}

1. TEM images of spherical micelles formed by self-assembly of $\mathrm{PS}_{51 \mathrm{k}}-b-\mathrm{P} 4 \mathrm{VP} \mathrm{P}_{18 \mathrm{k}}(\mathrm{PDP})_{0.1}$ in bulky solution.

2. TEM images of $\mathrm{PS}_{51 \mathrm{~K}}-b-\mathrm{P} 4 \mathrm{VP}_{18 \mathrm{~K}}(\mathrm{PDP})_{0.1}$ micelles obtained at different flow rate ratios $\left(V_{\mathrm{BCP}-\mathrm{THF}} / V_{\text {water }}\right)$.

3. TEM images of the aggregates formed by $\mathrm{PS}_{51 \mathrm{k}}-b-\mathrm{P}_{4} \mathrm{VP}_{18 \mathrm{k}}$ in microfluidic chips without adding PDP. 
4. Plot showing the change of average length of subunits by increasing the total flow rate.

5. TEM images of $\mathrm{PS}_{51 \mathrm{~K}}-b-\mathrm{P} 4 \mathrm{VP}_{18 \mathrm{~K}}(\mathrm{PDP})_{0.1}$ micelles obtained by self-assembly in bulk solution at various mixing rates.

6. TEM images of $\mathrm{PS}_{51 \mathrm{~K}}-b-\mathrm{P} 4 \mathrm{VP}_{18 \mathrm{~K}}(\mathrm{PDP})_{0.01}$ micelles obtained by self-assembly in bulk solution at various mixing rates.

7. TEM images of $\mathrm{PS}_{51 \mathrm{~K}}-b-\mathrm{P} 4 \mathrm{VP}_{18 \mathrm{~K}}(\mathrm{PDP})_{1.0}$ micelles obtained at different total flow rates in microfluidic chips.

8. TEM images of $\mathrm{PS}_{51 \mathrm{~K}}-b$-P4VP ${ }_{18 \mathrm{~K}}(\mathrm{PDP})_{1.0}$ micelles obtained by self-assembly in bulky solution at various mixing rates.

9. Morphology transition of $\mathrm{PS}_{51 \mathrm{k}}-b-\mathrm{P} 4 \mathrm{VP}_{18 \mathrm{k}}(\mathrm{PDP})_{0.01}$ SPNFs induced by mixing the as-prepared SPNFs solution with water in the microfluidic chips.

10. TEM images showing the transformation of SPNFs to spherical micelles under stirring.

11. TEM image showing the separated cylinders obtained by swelling the SPNFs in ethanol for more than $900 \mathrm{~min}$. 


\section{Supporting Figures:}

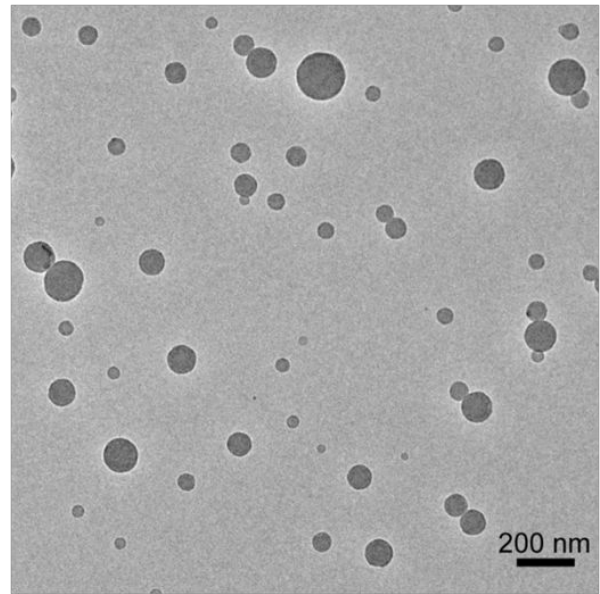

Figure S1. TEM images of spherical micelles formed by self-assembly of $\mathrm{PS}_{51 \mathrm{k}}-b-\mathrm{P} 4 \mathrm{VP}{ }_{18 \mathrm{k}}(\mathrm{PDP})_{0.1}$ in bulky solution. The $\mathrm{PS}_{51 \mathrm{~K}}-b-\mathrm{P} 4 \mathrm{VP}_{18 \mathrm{~K}}(\mathrm{PDP})_{0.1}$ solution $(1.0 \mathrm{mg} / \mathrm{mL})$ and water were mixed directly in beakers by syringe pumps. The adding rates of organic and aqueous phase were $V_{\mathrm{BCP}-\mathrm{THF}}=6.0$ $\mathrm{mL} / \mathrm{h}$ and $V_{\text {water }}=1.5 \mathrm{~mL} / \mathrm{h}$, respectively. 


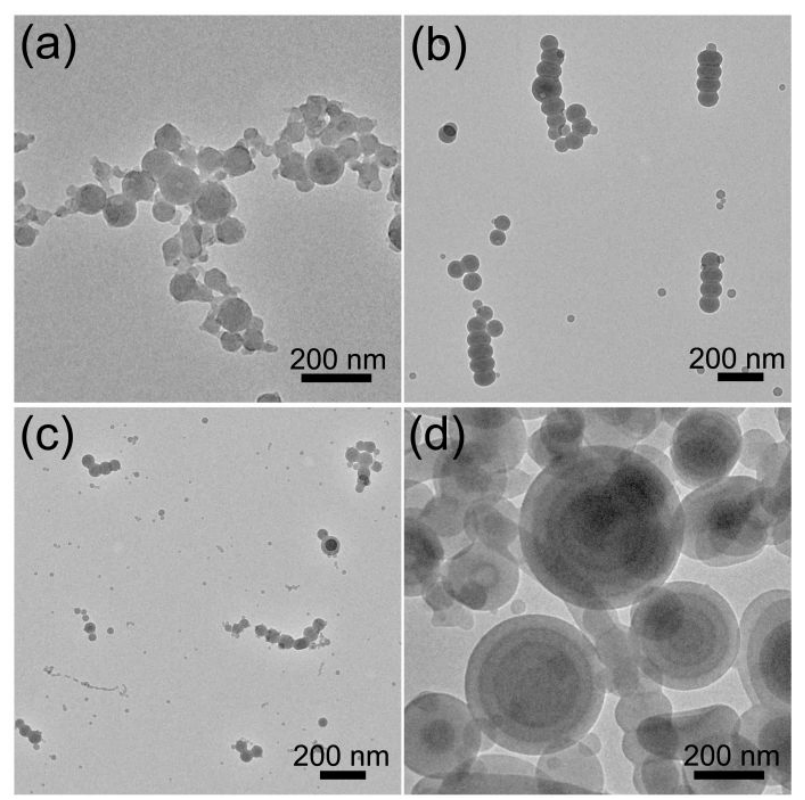

Figure S2. TEM images of $\mathrm{PS}_{51 \mathrm{~K}}-b-\mathrm{P} 4 \mathrm{VP}_{18 \mathrm{~K}}(\mathrm{PDP})_{0.1}$ micelles obtained at different flow rate ratios ( $V_{\mathrm{BCP}-\mathrm{THF}} / V_{\text {water }}$ ): (a) 0.1 ; (b) 1.0 ; (c) 2.0 ; (d) 6.0 . The concentration of $\mathrm{PS}_{51 \mathrm{~K}}-b-\mathrm{P} 4 \mathrm{VP}{ }_{18 \mathrm{~K}}(\mathrm{PDP})_{0.1}$ solution was $1.0 \mathrm{mg} / \mathrm{mL}$. 


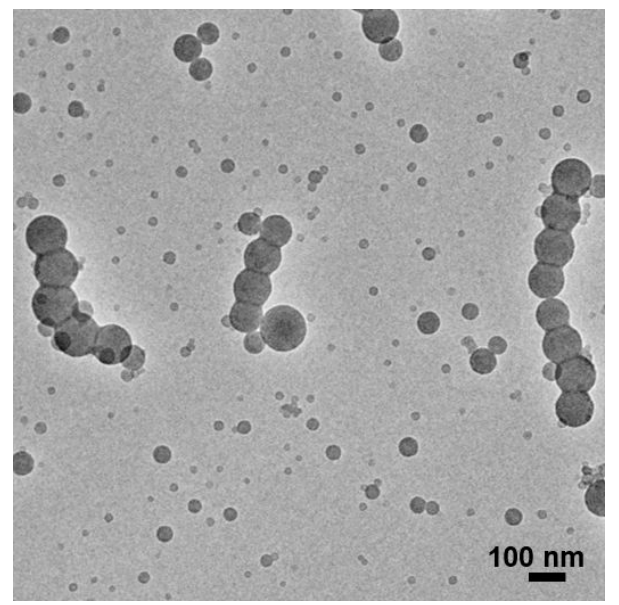

Figure S3. TEM images of the aggregates formed by $\mathrm{PS}_{51 \mathrm{k}}-b-\mathrm{P} 4 \mathrm{VP}_{18 \mathrm{k}}$ in microfluidic chips without adding PDP. The flow rates of organic and aqueous phase were $V_{\mathrm{BCP}-\mathrm{THF}}=6.0 \mathrm{~mL} / \mathrm{h}$ and $V_{\text {water }}=1.5$ $\mathrm{mL} / \mathrm{h}$, respectively. The concentration of BCP solution was $1.0 \mathrm{mg} / \mathrm{mL}$. 


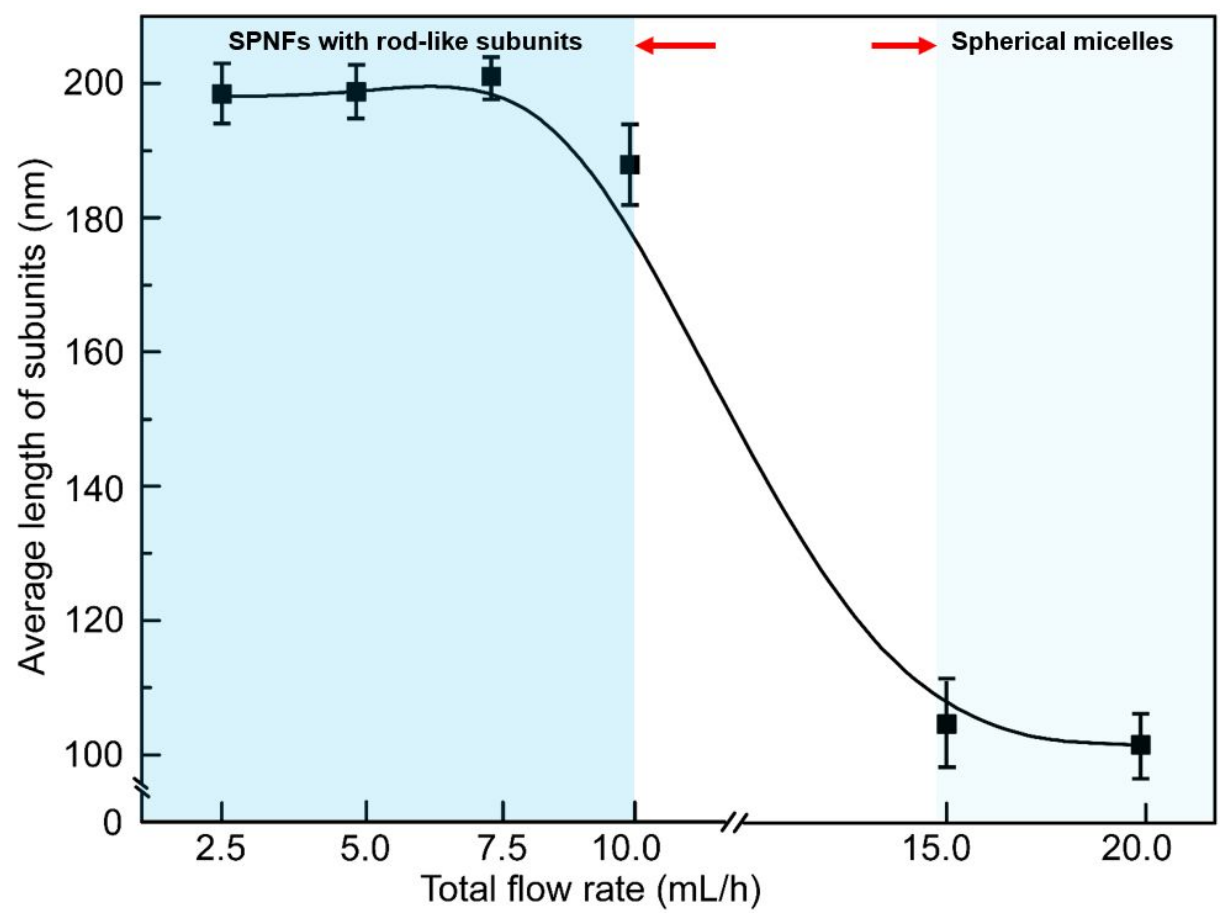

Figure S4. Plot showing the change of average length of subunits by increasing the total flow rate.

The results were obtained by measuring over 100 micelles. 

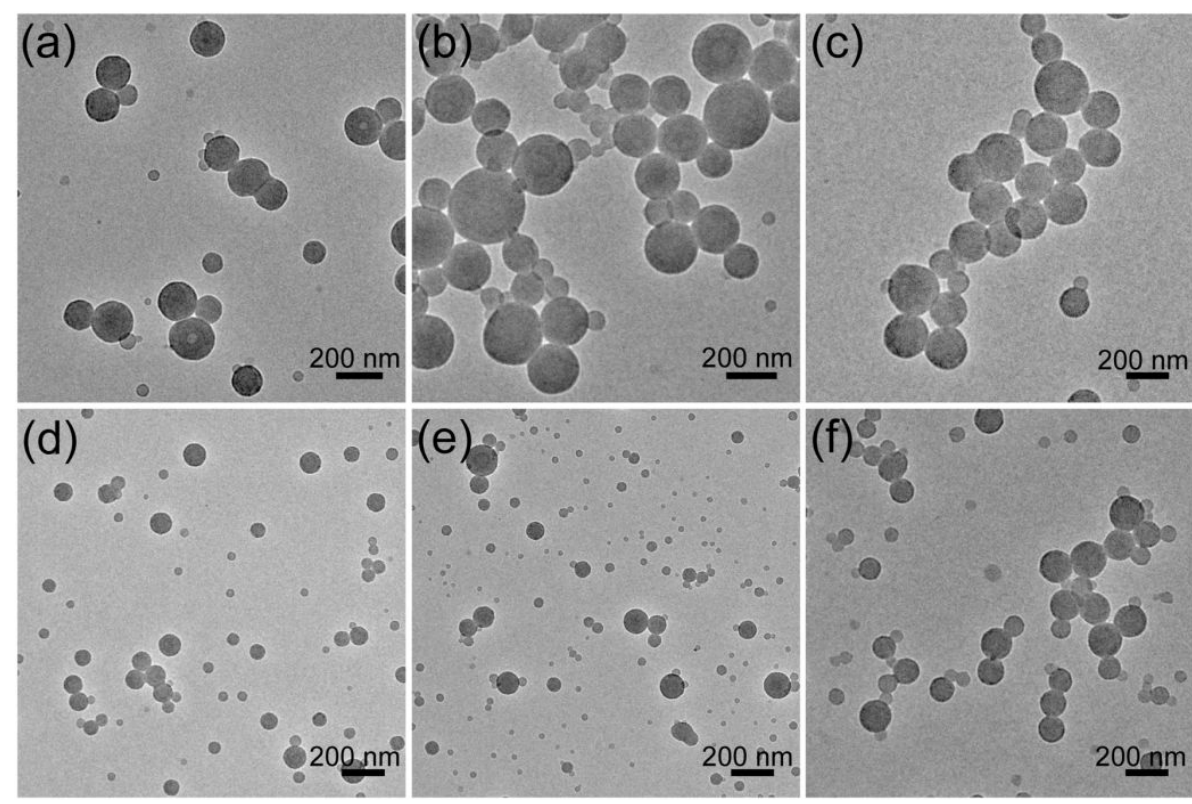

Figure S5. TEM images of $\mathrm{PS}_{51 \mathrm{~K}}-b-\mathrm{P} 4 \mathrm{VP}_{18 \mathrm{~K}}(\mathrm{PDP})_{0.1}$ micelles obtained by self-assembly in bulk solution at various mixing rates. $\mathrm{PS}_{51 \mathrm{~K}}-b-\mathrm{P} 4 \mathrm{VP}_{18 \mathrm{~K}}(\mathrm{PDP})_{0.1}$ solution $(1.0 \mathrm{mg} / \mathrm{mL})$ and water were mixed directly in beakers by syringe pumps. The total adding rates $\left(V_{\mathrm{BCP}-\mathrm{THF}}+V_{\text {water }}\right)$ were (a) 2.5 $\mathrm{mL} / \mathrm{h}$, (b) $5.0 \mathrm{~mL} / \mathrm{h}$, (c) $7.5 \mathrm{~mL} / \mathrm{h}$, (d) $10.0 \mathrm{~mL} / \mathrm{h}$, (e) $15.0 \mathrm{~mL} / \mathrm{h}$, and (f) $20.0 \mathrm{~mL} / \mathrm{h}$, respectively. The flow rate ratio $\left(V_{\mathrm{BCP}-\mathrm{THF}} / V_{\text {water }}\right)$ was kept at 4.0. 


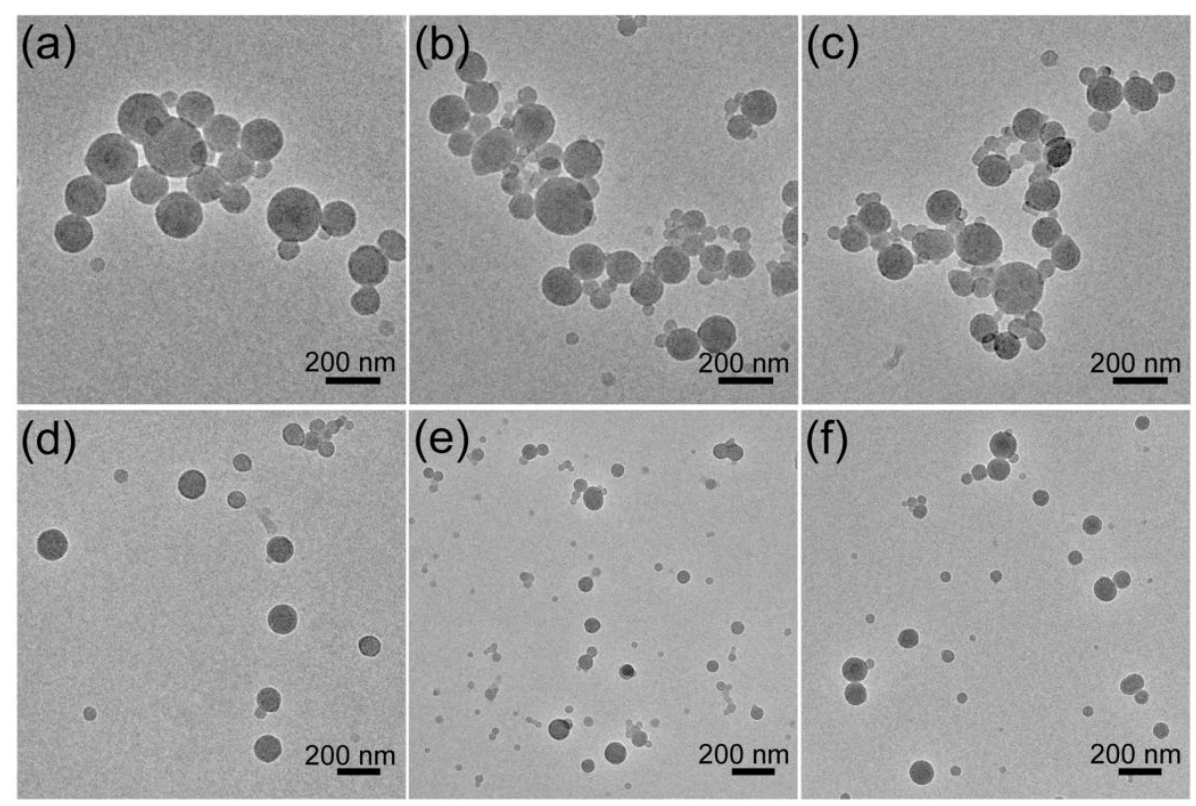

Figure S6. TEM images of $\mathrm{PS}_{51 \mathrm{~K}}-b-\mathrm{P} 4 \mathrm{VP}_{18 \mathrm{~K}}(\mathrm{PDP})_{0.01}$ micelles obtained by self-assembly in bulk solution at various mixing rates. $\mathrm{PS}_{51 \mathrm{~K}}-b-\mathrm{P} 4 \mathrm{VP}_{18 \mathrm{~K}}(\mathrm{PDP})_{0.01}$ solution $(1.0 \mathrm{mg} / \mathrm{mL})$ and water were mixed directly in beakers by syringe pumps. The total adding rates $\left(V_{\mathrm{BCP}-\mathrm{THF}}+V_{\text {water }}\right)$ were (a) 2.5 $\mathrm{mL} / \mathrm{h}$, (b) $5.0 \mathrm{~mL} / \mathrm{h}$, (c) $7.5 \mathrm{~mL} / \mathrm{h}$, (d) $10.0 \mathrm{~mL} / \mathrm{h}$, (e) $15.0 \mathrm{~mL} / \mathrm{h}$, and (f) $20.0 \mathrm{~mL} / \mathrm{h}$, respectively. The flow rate ratio $\left(V_{\mathrm{BCP}-\mathrm{THF}} / V_{\text {water }}\right)$ was kept at 4.0. 


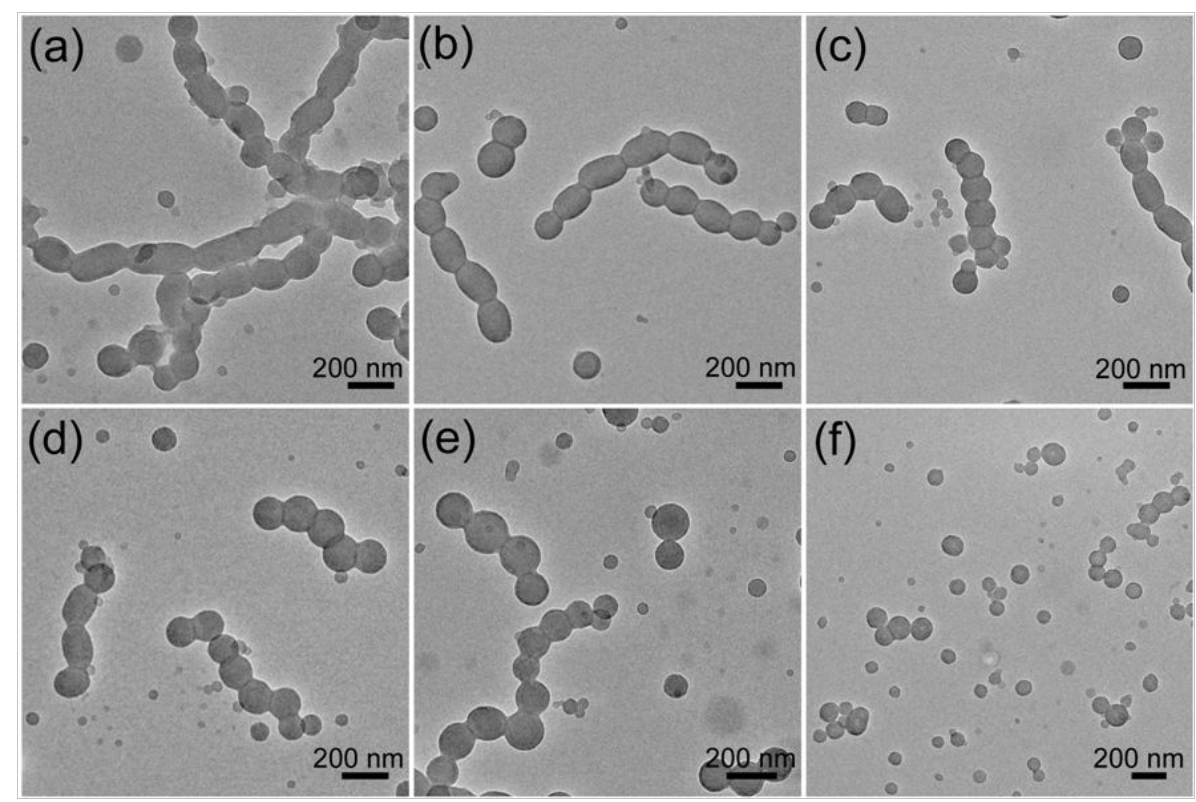

Figure S7. TEM images of $\mathrm{PS}_{51 \mathrm{~K}}-b-\mathrm{P} 4 \mathrm{VP}_{18 \mathrm{~K}}(\mathrm{PDP})_{1.0}$ micelles obtained at different total flow rates in microfluidic chips: (a) $2.5 \mathrm{~mL} / \mathrm{h}$; (b) $5.0 \mathrm{~mL} / \mathrm{h}$;(c) $7.5 \mathrm{~mL} / \mathrm{h}$; (d) $10.0 \mathrm{~mL} / \mathrm{h}$; (e) $15.0 \mathrm{~mL} / \mathrm{h}$; (f) 20.0 $\mathrm{mL} / \mathrm{h}$. The flow rate ratio $\left(V_{\mathrm{BCP}-\mathrm{THF}} / V_{\text {water }}\right)$ was kept at 4.0 . 

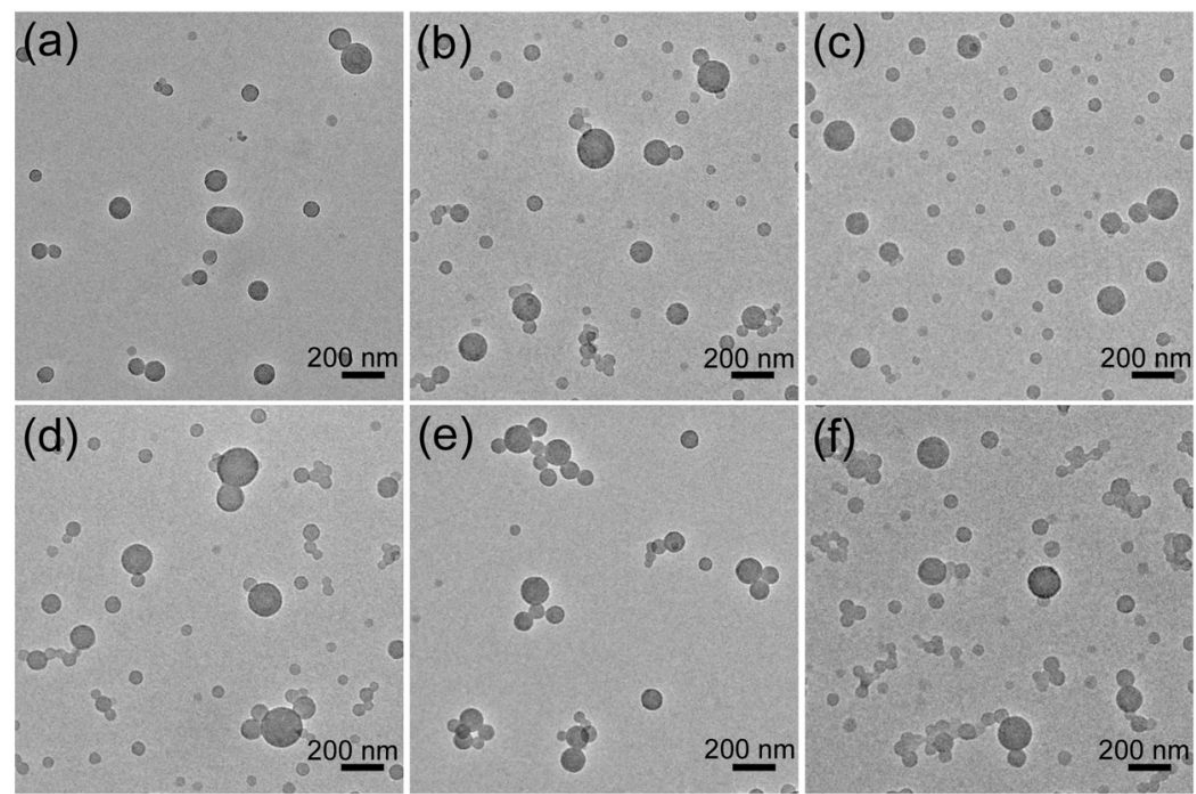

Figure S8. TEM images of $\mathrm{PS}_{51 \mathrm{~K}}-b-\mathrm{P} 4 \mathrm{VP}_{18 \mathrm{~K}}(\mathrm{PDP})_{1.0}$ micelles obtained by self-assembly in bulky solution at various mixing rates. $\mathrm{PS}_{51 \mathrm{~K}}-b-\mathrm{P} 4 \mathrm{VP}_{18 \mathrm{~K}}(\mathrm{PDP})_{1.0}$ solution $(1.0 \mathrm{mg} / \mathrm{mL})$ and water were mixed directly in beakers by syringe pumps. The total adding rates $\left(V_{\mathrm{BCP}-\mathrm{THF}}+V_{\text {water }}\right)$ were (a) 2.5 $\mathrm{mL} / \mathrm{h}$, (b) $5.0 \mathrm{~mL} / \mathrm{h}$, (c) $7.5 \mathrm{~mL} / \mathrm{h}$, (d) $10.0 \mathrm{~mL} / \mathrm{h}$, (e) $15.0 \mathrm{~mL} / \mathrm{h}$, and (f) $20.0 \mathrm{~mL} / \mathrm{h}$, respectively. The flow rate ratio $\left(V_{\mathrm{BCP}-\mathrm{THF}} / V_{\text {water }}\right)$ was kept at 4.0 . 
(a)
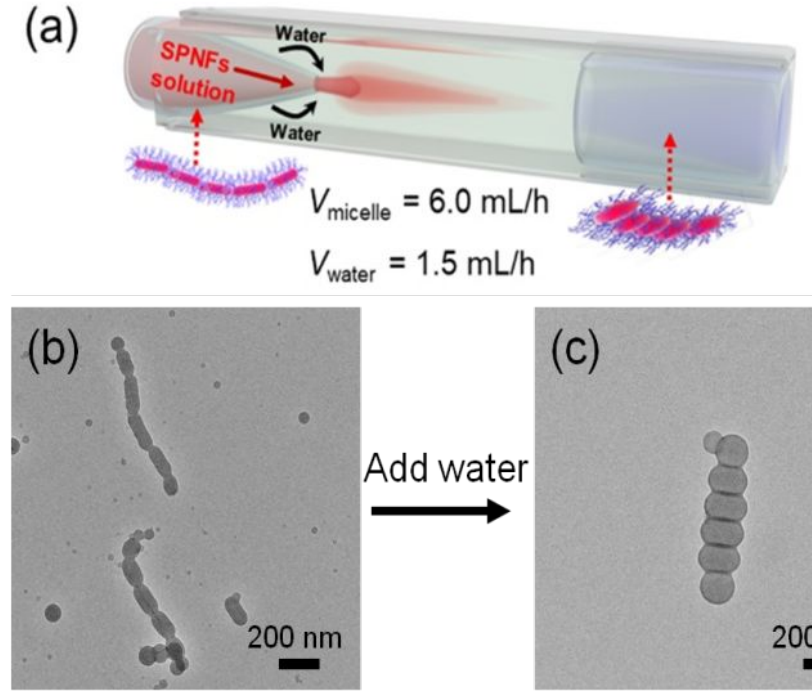

(c)

$200 \mathrm{~nm}$

Figure S9. Morphology transition of $\mathrm{PS}_{51 \mathrm{k}}-b-\mathrm{P}_{4} \mathrm{VP}_{18 \mathrm{k}}(\mathrm{PDP})_{0.01}$ SPNFs induced by mixing the as-prepared SPNFs solution with water in the microfluidic chips. (a) Schematic diagram showing the experimental process. (b)-(c) TEM images showing the transition of SPNFs upon adding water. The cartoon insets show the structure of SPNFs. 


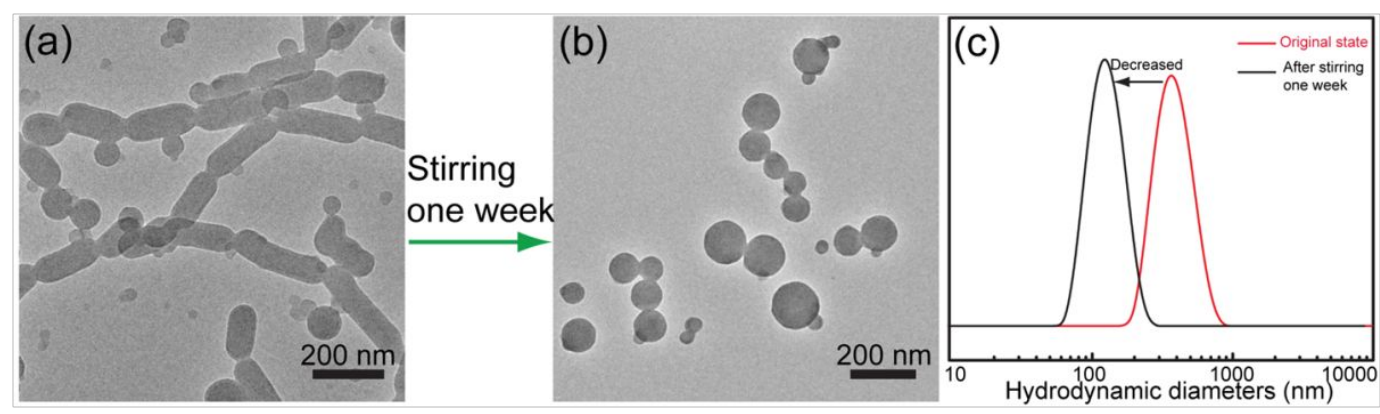

Figure S10. (a-b) TEM images showing the transformation of SPNFs to spherical micelles under stirring: (a) the original SPNFs; (b) spherical micelles obtained after stirring the SPNFs solution for one week. (c) DLS profiles of the SPNFs and spherical micelles. 




Figure S11. TEM image showing the separated cylinders obtained by swelling the SPNFs in ethanol for more than $900 \mathrm{~min}$. 